Research Article

\title{
The Economic Analysis on the Competitiveness of Small Towns with Sports Characteristics under the Guidance of "Diamond Model" Theory
}

\author{
Yan Xu 1 \\ Weifang Medical University, Weifang 261053, China \\ Correspondence should be addressed to Yan Xu; xuy202020@163.com
}

Received 9 August 2021; Revised 30 September 2021; Accepted 20 October 2021; Published 9 November 2021

Academic Editor: Daqing Gong

Copyright (c) 2021 Yan Xu. This is an open access article distributed under the Creative Commons Attribution License, which permits unrestricted use, distribution, and reproduction in any medium, provided the original work is properly cited.

\begin{abstract}
The sunrise industry of sports characteristic town under the transformation of economic development and the change of social demand contradiction is also a new growth point of sports industry economy. If we avoid homogeneous competition and improve the comprehensive competitiveness of small towns with sports characteristics, it will be a hot issue studied by scholars at home and abroad. The "Diamond Model" theory finds out the shortcomings of the development of sports characteristic towns by analyzing the factors of production, demand conditions, relevant supporting industries, and development strategies and puts forward the corresponding countermeasures. MATLAB simulation results show that the "Diamond Model" theory can improve the comprehensive competitiveness of sports characteristic towns, reduce the consumption of existing resources, and make a good prediction of the future development trend. Therefore, Porter's "Diamond Model" theory can provide guidance for the improvement of the comprehensive competitiveness of sports characteristic towns, and this study can provide theoretical and case support for relevant domestic research.
\end{abstract}

\section{Introduction}

Sports characteristic town is not only a new economic growth point of China's sports transformation, but also one of the important contents of sports development [1]. Sports featured towns can not only meet the needs of the public for sports products, but also provide an internal driving force for the rapid development of the sports industry [2]. Facing the homogenization of sports products, some scholars believe that the comprehensive development of sports can be realized through the integration of regional sports economy or the integration of sports model with other economic models. Some scholars also believe that the sports characteristic town is the embodiment of the comprehensive strength of the sports industry at a certain stage of sports development, which can not only meet the needs of the public for sports at this stage, but also realize the structural optimization of the sports industry [3]. How to quickly improve the comprehensive competitiveness of sports characteristic cities and towns and make them personalized is a hot spot in the field of sports economy and an urgent problem to be solved. The "Diamond
Model" theory holds that in the early stage of development, any industry needs to plan from production factors, demand conditions, relevant supporting industries, and development strategies, so as to lay the foundation for the improvement of comprehensive competitiveness in the later stage [4]. To sum up, scholars at home and abroad have increased the research on the economy of sports industry, but most of them focus on qualitative analysis or theoretical analysis, lacking comprehensive analysis methods. Based on this background, based on the "Diamond Model" theory, this paper analyzes the development of sports characteristic towns and finds out the scheme to improve their competitiveness.

\section{Mathematical Description of the Competitiveness of Small Towns with Sports Characteristics}

Sports featured town is the comprehensive result of the highquality development of social economy, the improvement of comprehensive fitness demand and the development of urbanization to a certain stage, taking into account many 
functions such as fitness, entertainment, and physical exercise [5]. Sports featured towns not only promote local economic development, but also improve the comprehensive competitiveness of local sports. Correctly guiding the development of sports characteristic towns is the key to improve their comprehensive competitiveness [6]. At present, the research on sports characteristic towns stays at the theoretical level or uses qualitative analysis methods, lacks scientific and objective comprehensive analysis methods, and cannot accurately guide the improvement of comprehensive competitiveness. In addition, the research on the competitiveness of sports characteristic towns involves a large amount of data, which needs comprehensive analysis in order to make accurate analysis.

2.1. Factors Affecting the Competitiveness of Sports Characteristic Towns. The "Diamond Model" theory holds that production factors, demand conditions, relevant supporting industries, and development strategies are the four aspects that affect the sports characteristic town [7]. It is necessary to collect relevant data and conduct comprehensive analysis with the help of net, SQL, network cloud, and Internet, so as to provide a scheme for improving the comprehensive competitiveness.

Assuming that the economic set of competitiveness of small towns with sports characteristics is $C$, production factors $x_{i}$, demand conditions $x_{j}$, relevant supporting industries $x_{k}$, and development strategy $x_{l}$, then $C=\left\{c_{i}\right\}=\sum_{i=1}^{n} x_{i} \cap \sum_{j=1}^{n} x_{j} \cap \sum_{k=1}^{n} x_{k} \cap \sum_{l=1}^{n} x_{l}$. The contents of each factor are shown in Table 1 .

\subsection{Mathematical Description of Influencing Factors Affecting} the Competitiveness of Sports Characteristic Towns. The "Diamond Model" theory is a guiding theory for the early development of sports, which is suitable for improving the competitiveness of small towns with sports characteristics. Because the sports characteristic town is in the development stage, it is quite different from the traditional economic sports in economic development. Accurately finding the key point of development is the key to the economic analysis of the competitiveness of sports characteristic town [8]. The competitiveness of sports featured towns includes sports, entertainment, and other aspects. In order to accurately find the balance point of economic development, it is necessary to make a comprehensive analysis from the aspects of production factors, demand conditions, relevant supporting industries, and development strategies, combined with the corresponding economic development. The influencing factors are analyzed according to the "Diamond Model" theory as shown in Figure 1.

According to the above analysis, the relationship between various factors in the "Diamond Model" theory is $n$ : $n$, and the competitiveness of sports characteristic towns is affected by economic environment and external opportunities. In other words, the improvement of the competitiveness of small towns with sports characteristics depends on national policies, socioeconomic development, and relevant structures [9]. In order to better analyze the competitiveness of sports characteristic towns, the economic data accuracy of the competitiveness of sports characteristic towns is required to be $95-99 \%$, so as to reduce the consumption of existing resources and make a good prediction of the future development trend.

(1) In the economic set of $C, i$ is entertainment content, $j$ is related industries, $k$ is the development of the town (good development $=1$, lagging development $=0$ ), $l$ is the number of economic indicators, and $m$ is the comprehensive competitiveness [10]. Then, the economic set of the competitiveness of small towns with sports characteristics can be described as $C_{i, j, k}$, $l, m$, where $i, j, k, l, m=(1,2, \ldots, n), n$ is a natural number.

(2) Sports characteristic town data processing: the economic analysis of the competitiveness of sports characteristic towns should be based on the "Diamond Model" theory to process the data in net, SQL, network cloud, and Internet. This paper uses $K$ means to judge the competitiveness data of all sports characteristic towns obtained, and the different attributes and classifications of economic data [11] will affect the analysis results. In order to simplify the calculation process and quantitatively display the analysis content and collected data in the "Diamond Model" theory, various attributes need to be standardized to make them projected in the range of $0-1$. The competitiveness data processing of sports characteristic towns can be expressed by functions $A(m \cdot I)$, where $m$ is the attribute of the obtained data, and $I$ is the data obtained from net, SQL, and network cloud. The data processing formula can be obtained by integrating the function $A(m \cdot I)$ with $K$-means; the result is shown in the following formula:

$$
\sum_{i=0}^{n} I_{i}=|S|
$$

where $S$ is the distance result of $K$-means to the information and $I$ is the obtained information. Because the competitive data of sports characteristic towns obtained from net, SQL, and network cloud is only the amount of comparative values, the source of values and other attributes can be ignored. The calculation method of European distance similarity $J$ can be used to replace $S$ value, and formula (1) can be transformed into the following formula:

$$
J(A, B)=\frac{|A \cap B|}{|A \cup B|}
$$

(3) Comprehensive competitiveness of sports featured towns: the matching degree between the external economic environment and the development of sports characteristic towns determines the development potential of sports characteristic towns [12]. In order to simplify the calculation process, the 
TABLE 1: Influencing factors of sports characteristic town competitiveness.

\begin{tabular}{lccc}
\hline Influence factor & Parameter content & Influence factor & Parameter content \\
\hline $\begin{array}{l}\text { Production } \\
\text { factors } x_{i}\end{array}$ & Industrial projects of sports featured towns & Related supporting & Sports economy, sports competition, \\
$\begin{array}{l}\text { Demand } \\
\text { conditions } x_{j}\end{array}$ & Market and society's demand for the industrial & industries $x_{k}$ & Development \\
\hline
\end{tabular}

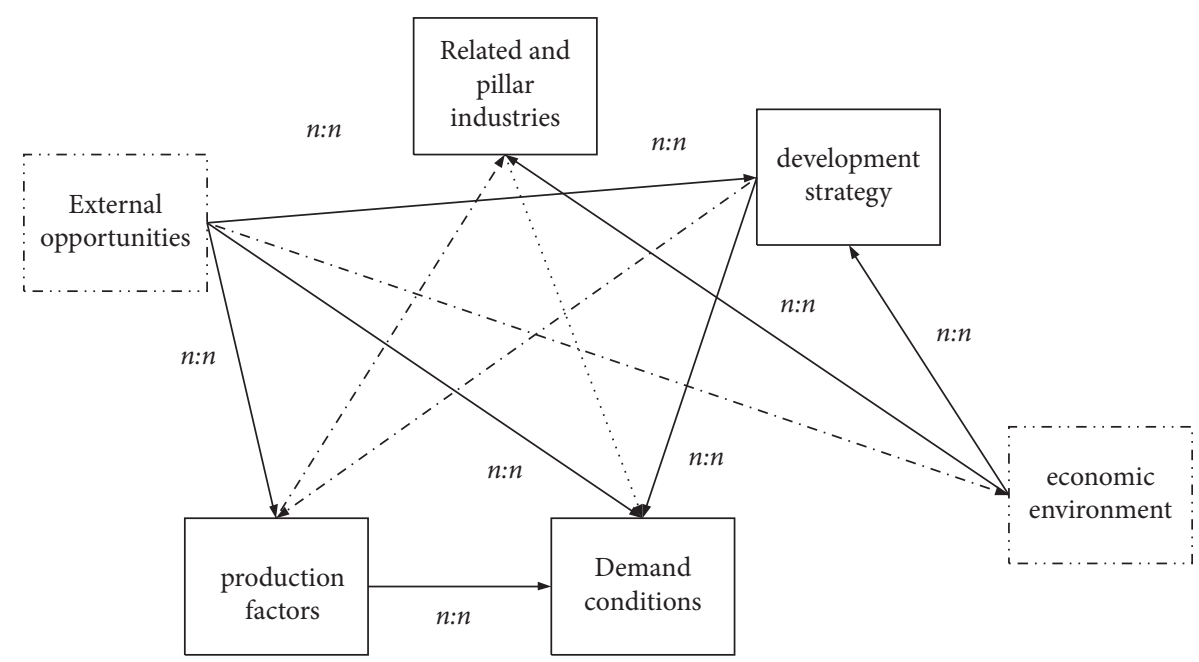

Figure 1: Relationship between influencing factors in the "Diamond Model" theory.

external economic environment and the development of small towns with sports characteristics can be quantified, and the occurrence frequency can be used to calculate the relationship between the two. Assuming that $G_{i}$ is the frequency of $i$ indicator in the external economic environment, $G_{j}$ is the frequency of $j$ indicator in the development of sports characteristic towns, $G_{i j}$ is the frequency of $i$ indicator and $j$ indicator in the external economic environment, and $H$ is the frequency coefficient of $G_{i j}$ (constant term obtained from the statistical yearbook of sports industry), then the external economic environment. The matching degree between the development of sports characteristic towns is expressed as follows:

$$
\frac{H \cdot G_{i j}}{G_{i}+G_{j}}=R
$$

(4) According to $G_{i j}$ that is above frequency in the analysis of sports characteristic towns, a comprehensive competitiveness set $N$ is formed $C_{i, j, k, l, m}$, that is, the processed data set $N_{i, j, k, l, m}$.

(5) In order to improve the accuracy of competitiveness analysis of sports characteristic towns, it is necessary to preset the consumption of resources, the accuracy of future development trend, the accuracy and threshold of production factors, demand conditions, relevant supporting industries, and development strategies [13].

(6) We should reduce the interference factors in the process of data processing, such as policy changes, economic trends, etc. [14]. In this paper, the antiinterference ability is expressed by calculating the interference degree. The specific calculation formula is expressed as follows:

$$
P=x y z o+\xi
$$

Among them, $P$ is the anti-interference ability of sports characteristic town competitiveness analysis, that is, the interference caused by immutable factors; $\xi$ is the interference adjustment coefficient, that is, the average anti-interference ability of the whole industry (data source: statistical data analysis of sports industry).

\section{Economic Analysis Model of the Competitiveness of Small Towns with Sports Characteristics under the "Diamond Model" Theory}

3.1. Construction of Economic Analysis Model. Genetic algorithm (GA) judges and analyzes the competitiveness of sports characteristic towns through repeated iteration of previous data and combined with the relevant standards of "Diamond Model" theory, so as to help Chinese sports characteristic towns predict resource consumption and future development trend [15]. GA algorithm traverses the competitiveness data of sports characteristic towns obtained from net, SQL, and network cloud, analyzes the production factors $x_{i}$, demand conditions $x_{j}$, relevant supporting industries $x_{k}$, and development strategies $x_{l}$, judges the 
relevant parameters, and obtains the results of resource consumption and future development trend prediction [16]. In order to improve the judgment effect of the competitiveness of sports characteristic towns, the Metropolis acceptance criterion of annealing simulation algorithm is calculated from the "Diamond Model" theory, and the corresponding threshold and preset values are obtained. The competitiveness of sports characteristic towns is judged, and the corresponding $p$ value is obtained, so as to strengthen the constraint on the competitiveness of sports characteristic towns and avoid repeated data judgment, or not in line with the judgment results of the "Diamond Model" theory.

\subsection{Economic Design of Competitiveness of Sports Charac-} teristic Towns. The Judgment of "Diamond Model" theory [17]: because the "Diamond Model" theory involves many related attributes, although the early $K$-mean clustering is carried out, its judgment is still difficult. It needs to be combined with genetic algorithm (GA) for comprehensive analysis, so as to obtain the economic judgment results of the competitiveness of sports characteristic towns with high accuracy. From the above analysis, it can be seen that the economic set $N_{i, j, k, l, m}$ of the competitiveness of small towns with sports characteristics, then the economic set of the competitiveness of all small towns with sports characteristics should be $\sum_{i=1, j=1}^{A, B} N_{i, j, k, l, m}$. After constructing the data description of the economic set of the competitiveness of small towns with sports characteristics, it is necessary to analyze the compliance of each economic index from the "Diamond Model" theory. Since $K$ is the economic development ( $\operatorname{good}=1, \operatorname{lag}=0$ ), the matching degree between the external economic environment and the development of the small town with sports characteristics can be judged. If the matching degree is good and meets the preset relevant standards, then $k=1$. If the matching does not meet the requirements or does not meet the relevant standards, then $k=0$.

The accuracy design of sports characteristic town competitiveness judgment: accuracy is the key to judge the competitiveness of small towns with sports characteristics. It is the comparison between resource consumption, prediction of future development trend and actual results. In order to reduce the influence of subjective factors on the calculation results, we can set an appropriate function to guide the iterative direction of genetic algorithm and make the development of iterative calculation results. Assuming that there is a large deviation between the theoretical prediction and the actual effect, it is necessary to set the initial threshold or calculate the threshold to control the calculation results of the prediction. Generally speaking, the error between actual effect and theoretical selection should be controlled between 0.01 and 0.05 . In this paper, 0.01 is used for simulation analysis, and the appropriate function is analyzed. The specific calculation formula is expressed as follows:

$$
f=\min \left\{\max _{k \in 1,2,3, \ldots, m}\left(A_{k}\right)+\xi \sum_{i \in 1,2, \ldots, n} \max \left(t_{1}-t_{i}\right)\right\} .
$$

Among them, $A_{k}$ is the difference between theory and practical effect; $t_{1}$ is the degree of impact on the prediction results; and $t_{i}$ is the external economic environment and the development of the town with sports characteristics. Through the above analysis, it can be seen that each selection is based on the comprehensive competitiveness of sports characteristic towns, so as to predict the resource consumption and future development trend.

3.3. Index Adjustment Design. Index adjustment design is a method to indirectly improve the judgment accuracy of the competitiveness of small towns with sports characteristics, which mainly involves production factors $x_{i}$, demand conditions $x_{j}$, relevant supporting industries $x_{k}$, and development strategies $x_{l}$. The above judgments are the criteria for comprehensively analyzing the competitiveness of small towns with sports characteristics and also the premise to ensure the positive progress of economic indicators. Under the constraints of metropolis's acceptance criteria, the calculation formula of the above indicators is expressed as follows:

$$
\sum_{k=x, y, z, o, i=1}^{n} P_{l_{k}} \begin{cases}N_{i, j, 1,0}, & f_{m} \leq f_{m g}, \\ k_{i} \frac{\left(f_{m}-f_{\min }\right)}{\left(f_{m g}-f_{\min }\right)}, & f_{m}<f_{m g},\end{cases}
$$

where $N_{i, j, 0,0}$ is the initial judgment; it is recognized as none, and whether $f_{\text {min }}$ is selected as 0 , that is, the data has not been analyzed. $f_{m g}$ is the minimum accuracy of relevant data calculation; $f_{c}$ refers to the influence of external influencing factors or uncontrollable factors on the calculation results.

3.4. Steps to Judge the Competitiveness of Sports Characteristic Towns. Based on the above analysis methods, the judgment steps of the competitiveness of sports characteristic towns can be obtained, and the specific contents are as follows:

(1) We should comprehensively analyze the existing external economic environment, assign values to various information, construct economic set $n$, and then assign values to production factors $x_{i}$, demand conditions $x_{j}$, relevant supporting industries $x_{k}$, and development strategies $x_{l}$. We should set the initial values more accurately and comprehensively. Based on the theory of "Diamond Model," this paper judges the economic trend, that is, $K$ value. At the same time, the accuracy of the results should be analyzed to make it meet the set threshold [30].

(2) According to metropolis acceptance criteria, the degree of external interference, analyze the matching degree between the external economic environment and the development of sports characteristic towns. If the matching result exceeds 0.01 or other preset threshold, the matching level shall be reduced. 
TABle 2: The visit to characteristic towns.

\begin{tabular}{|c|c|c|c|c|}
\hline Economic indicators & Node work content & Number of visits & Amount of data accessed & Interference times \\
\hline Local sports & Comprehensive sports town & 27 & 68 & 2 \\
\hline National famous sports town & Comprehensive sports town & 22 & 25 & 3 \\
\hline Badminton sports town & Comprehensive sports town & 39 & 77 & 4 \\
\hline Tennis sports town & Comprehensive sports town & 95 & 67 & 2 \\
\hline Swimming sports town & International swimming competition & 13 & 62 & 7 \\
\hline Swimming sports town & Outdoor survival and outdoor economy & 70 & 55 & 6 \\
\hline $\begin{array}{l}\text { Comprehensive sports town } \\
\text { Com. }\end{array}$ & CBA, events, etc. & $\begin{array}{c}\cdots \ldots \\
29\end{array}$ & ${ }_{95} \cdots \cdots$ & $\cdots \cdots \cdots$ \\
\hline
\end{tabular}

TABle 3: Data transfer of sports characteristic towns.

\begin{tabular}{|c|c|c|c|c|c|}
\hline Sports type & Access time $(\mathrm{s})$ & Access data size & Access data size & Clustering degree (\%) & Clustering degree (\%) \\
\hline \multicolumn{6}{|c|}{0.05 accuracy } \\
\hline Accuracy $x_{i}$ & 21 & 81 & 17 & 90 & 13 \\
\hline Demand conditions $x_{j}$ & 11 & 62 & 17 & 90 & 9 \\
\hline Related supporting industries $x_{k}$ & 17 & 57 & 13 & 94 & 8 \\
\hline Development strategy $x_{l}$ & 16 & 60 & 17 & 97 & 5 \\
\hline \multicolumn{6}{|c|}{0.04 accuracy } \\
\hline Accuracy $x_{i}$ & 17 & 68 & 6 & 93 & 2 \\
\hline Demand conditions $x_{j}$ & 16 & 30 & 8 & 90 & 3 \\
\hline Related supporting industries $x_{k}$ & 11 & 76 & 2 & 96 & 1 \\
\hline Development strategy $x_{l}$ & 13 & 49 & 4 & 90 & 3 \\
\hline \multicolumn{6}{|c|}{0.03 accuracy } \\
\hline Accuracy $x_{i}$ & 15 & 54 & 13 & 92 & 7 \\
\hline Demand conditions $x_{j}$ & 16 & 37 & 7 & 93 & 2 \\
\hline Related supporting industries $x_{k}$ & 16 & 61 & 4 & 97 & 2 \\
\hline Development strategy $x_{l}$ & 18 & 55 & 12 & 92 & 5 \\
\hline \multicolumn{6}{|c|}{0.02 accuracy } \\
\hline Accuracy $x_{i}$ & 24 & 59 & 13 & 98 & 4 \\
\hline Demand conditions $x_{j}$ & 19 & 43 & 4 & 94 & 1 \\
\hline Related supporting industries $x_{k}$ & 13 & 94 & 6 & 91 & 2 \\
\hline Development strategy $x_{l}$ & 19 & 94 & 5 & 94 & 12 \\
\hline \multicolumn{6}{|c|}{0.01 accuracy } \\
\hline Accuracy $x_{i}$ & 11 & 84 & 6 & 94 & 1 \\
\hline Demand conditions $x_{j}$ & 15 & 81 & 6 & 93 & 4 \\
\hline Related supporting industries $x_{k}$ & 10 & 52 & 8 & 95 & 6 \\
\hline Development strategy $x_{l}$ & 19 & 30 & 8 & 98 & 6 \\
\hline
\end{tabular}

(3) If the matching degree meets the requirements of relevant standards, the calculation results will be included in the economic index adoption set $O$.

(4) If the economic set $n$ is not completely traversed, go to step 3 and repeat the calculation until all economic set $n$ points are traversed.

(5) The output economic index adopts set $O$, and ends the analysis, and the operation is terminated.

\section{Economic Model Verification of "Diamond Model" Theory and Competitiveness of Small Towns with Sports Characteristics}

4.1. Overview of Sports Featured Towns. Take the economic development study of small towns with Chinese sports characteristics from 2019 to 2020 as an example. All data sources: official data for relevant comparative analysis. Set the number of iterations of policy analysis to 200, the analysis accuracy of each data is 0.01 , and a total of 2728 accesses to net, SQL, and network cloud. Among them, there are 102 production factors $x_{i}$ in total. Demand conditions $x_{j}$, 230 in total; relevant supporting industries $x_{k}, 902$ in total, development strategies $x_{k}, 402$ in total, database addresses are accessed. The result is shown in Table 2.

4.2. Test Indicators. In order to further analyze the stability of the economic model of the competitiveness of small towns with sports characteristics, the model needs to be tested repeatedly to ensure that its output results meet the relevant requirements.

The $K$-mean data processing results. Firstly, $k$-mean cluster analysis is carried out for entertainment information $N_{i, j, k, l, m}$ and $m$. In the process of multiple iterations, the assignment of production factors $x_{i}$, demand conditions $x_{j}$, related supporting industries $x_{k}$, and development strategy $x_{l}$ is greater than $90 \%$, indicating that the overall processing situation is ideal. At the same time, in the process of data clustering, the number of data accesses reaches 6728 times. 


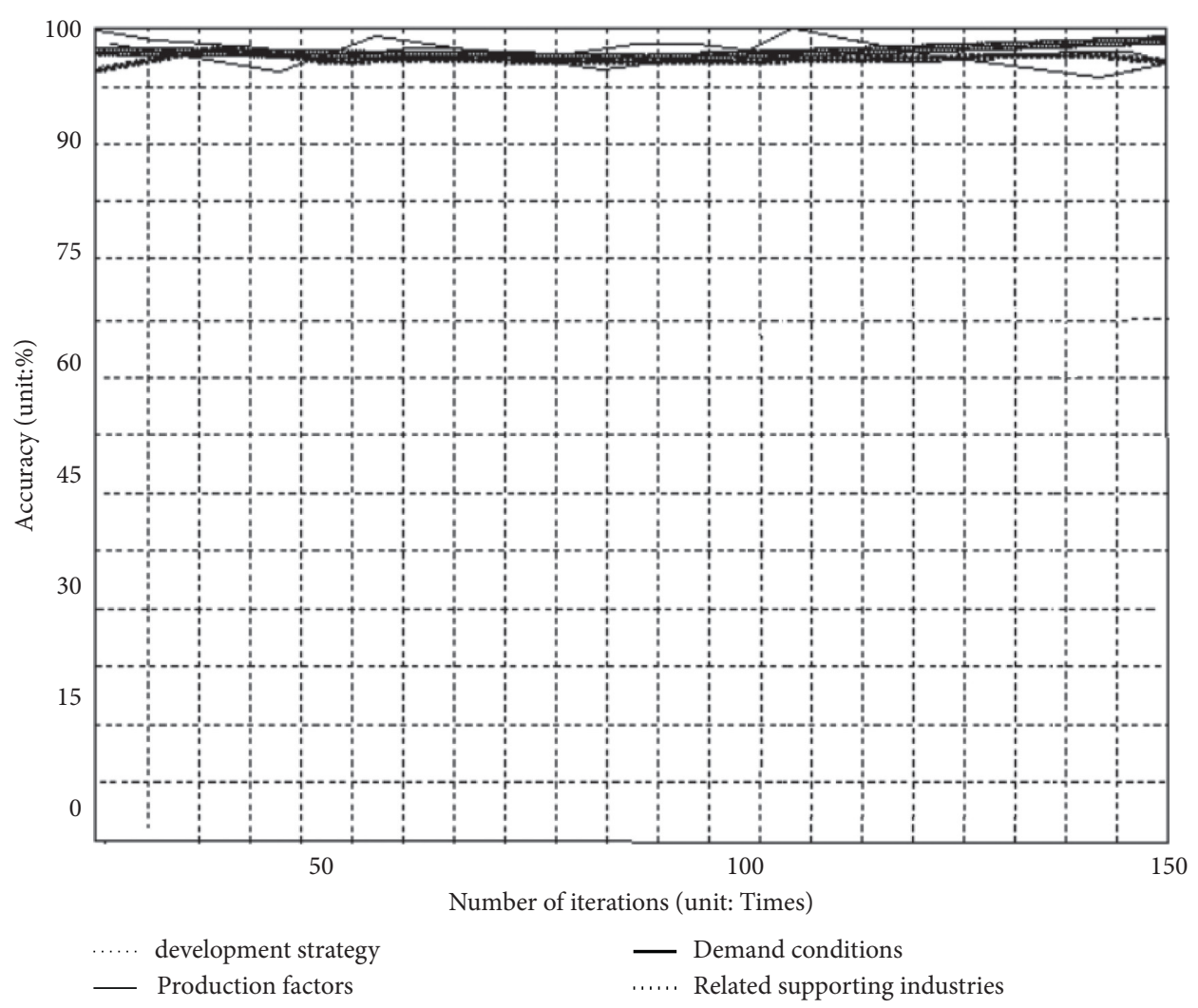

Figure 2: Accuracy of production factors, demand conditions, relevant supporting industries, and development strategies.

This shows that the clustering of each data is difficult, and the satisfactory processing effect can be achieved only after repeated iterative processing. The result is shown in Table 3.

It can be explained that under the accuracy standard of $0.01-0.05$, the accuracy of data processing is high, and there is no significant change in the results due to the change of $K$-mean clustering degree, all of which are $>90 \%$.

\subsection{Resource Consumption and Accuracy of Future Devel-} opment Trend Prediction. In order to verify the accuracy of the whole model, we can calculate its production factors $x_{i}$, demand conditions $x_{j}$, related supporting industries $x_{k}$, and development strategy $x_{l}$ to judge whether its accuracy meets the actual requirements. According to the results of relevant tests, the accuracy of production factor $x_{i}$, demand condition $x_{j}$, relevant supporting industry $x_{k}$, and development strategy $x_{l}$ is greater than $90 \%$, and the accuracy of production factor $x_{i}$, demand condition $x_{j}$, and relevant supporting industry $x_{k}$ is greater than $95 \%$, mainly because the industry survey data is stable and less affected by external policies and objective conditions.

Through the development strategy $x_{l}$ analysis, it is found that the external interference has little impact on the whole result, mainly because this paper carries out $k$-mean cluster analysis on the previous data, standardizes the data, and simplifies the impact of other attributes of the data on the result, so as to reduce the impact of external interference on the accuracy of the measurement result. In short, production factors $x_{i}$, demand conditions $x_{j}$, relevant supporting industries $x_{k}$, and development strategies $x_{l}$ meet the expected setting requirements. The result is shown in Figure 2.

4.4. Analysis of Resource Consumption and Prediction Results of Future Development Trend. According to the "Diamond Model," the resource consumption and future development trend are predicted, and it is found that the overall prediction accuracy can be more than 90\%. Although the prediction accuracy decreases with the extension of external interference and prediction time, it is still greater than $90 \%$. This shows that the resource consumption and future development trend are in line with the actual situation, and the corresponding strategy analysis can be carried out.

\section{Conclusion}

Sports characteristic town is a new economic growth point of China's sports transformation. It can not only meet the needs of the public for sports products, but also provide an internal driving force for the rapid development of the sports industry [18]. At present, the low level of comprehensive competitiveness and inaccurate prediction of future development of sports characteristic towns increase the risk of the development of sports characteristic towns. In order to solve the above problems, this paper proposes a competitive analysis method of sports characteristic towns based on $k$-clustering, in order to improve the accuracy of result analysis. Firstly, the $k$-clustering method is used to analyze the relevant information in the characteristic town, 
construct the relationship between production factors $x_{i}$, demand conditions $x_{j}$, relevant supporting industries $x_{k}$, and development strategy $x_{l}$, and realize the key numerical extraction of relevant data. Then, by setting the threshold of the corresponding value, the calculation direction is constrained to be positive to avoid local extremum. In addition, there are significant differences between the external economic environment and the development of small towns with sports characteristics. The purpose of model analysis is how to use the "Diamond Model" theory to analyze their positions and find the key points between them. Through MATLAB simulation analysis, the results show the following: (1) the production factor $x_{i}$, demand condition $x_{j}$, relevant supporting industries $x_{k}$, and development strategy $x_{l}$ are calculated accordingly. The results show that the accuracy of the above standards is greater than $90 \%$, and the accuracy of production factor $x_{i}$, demand condition $x_{j}$, and relevant supporting industries $x_{k}$ is greater than $95 \%$. The main reason is that the industry survey data is stable and subject to external policies. The influence of objective conditions is small. (2) According to the "Diamond Model," the resource consumption and future development trend are predicted, and it is found that the overall prediction accuracy can be more than $90 \%$. Although the prediction accuracy decreases with the extension of external interference and prediction time, it is still greater than $90 \%$. On the whole, this paper accurately selects the data of the competitiveness of sports characteristic towns, so as to provide guidance for the prediction of resource consumption and future development trend.

\section{Data Availability}

The data used to support the results of this research are not convenient to provide.

\section{Conflicts of Interest}

The author declares that there are no conflicts of interest regarding the publication of this study.

\section{References}

[1] Y. Zhong, "Large power grid intelligent regulation system framework under big data and artificial intelligence," China new communications, vol. 23, no. 1, pp. 63-64, 2021.

[2] T. Nguyen, Q. Pham, X. Dang, T. Doan, and X. Le, "Optimization parameters of milling process of mould material for decreasing machining power and surface roughness criteria," Tehnicki vjesnik-Technical Gazette, vol. 26, no. 5, pp. 12971304, 2021.

[3] F. Zheng, M. Tang, and J. Ma, "Big data analysis of North Myanmar power grid fault," Yunnan hydropower, vol. 37, no. 1, pp. 189-194, 2021.

[4] L. Jian, X. Guo, and Y. Rao, "Power grid diagnosis method under $220 \mathrm{kV}$ based on power grid big data," Automation and instrumentation, vol. 13, no. 10, pp. 211-214, 2020.

[5] L. Yao, W. Yang, and W. Huang, "An improved feature-based method for fall detection," Tehnicki vjesnik-Technical Gazette, vol. 26, no. 5, pp. 1363-1368, 2021.
[6] M. Liu, L. Zhou, and Y. Liu, "Research on the application of big data and artificial intelligence technology in anti stealing monitoring," Electronic components and information technology, vol. 4, no. 10, pp. 46-47, 2020.

[7] W. Yu, G. Hou, P. Xia, and J. Li, "Supply chain joint inventory management and cost optimization based on ant colony algorithm and fuzzy model," Tehnicki vjesnik-Technical Gazette, vol. 26, no. 6, pp. 1729-1737, 2021.

[8] S. Tosun, A. Öztürk, and F. Taşpinar, "Short term load forecasting for Turkey energy distribution system with artificial neural networks," Tehnicki vjesnik-Technical Gazette, vol. 26, no. 6, pp. 1545-1553, 2021.

[9] Y. Xu and J. Li, "Application of big data image processing technology in smart grid," Information and computer (theoretical Edition), vol. 32, no. 23, pp. 166-168, 2021.

[10] S. F. Mohamed and A. B. Amin, "Management of supply chain in construction management: roles and responsibilities," Journal of System and Management Sciences, vol. 8, no. 4, pp. 1-12, 2021.

[11] T. H. Nazifa and K. K. Ramachandran, "Exploring the role of information sharing in supply chain management: a case study," Journal of System and Management Sciences, vol. 8, no. 4, pp. 13-37, 2021.

[12] M. M. Alam and F. Faisal, "Public-private partnership (PPP) projection Bangladesh: current status and challenges," Journal of System and Management Sciences, vol. 8, no. 4, pp. 38-56, 2021.

[13] I. Hut, B. Jeftic, L. Matija, Z. Cojbasic, and D. Koruga, "Machine learning classification of cervical tissue liquid based cytology smear images by optomagnetic imaging spectroscopy," Tehnicki vjesnik-Technical Gazette, vol. 26, no. 6, pp. 32-33, 2021.

[14] A. Burinskiene, "Pharma supply chain: efficiency modelling approach," Journal of System and Management Sciences, vol. 8, no. 2, pp. 65-73, 2021.

[15] Y. Guo, "Research on power grid planning under the background of power big data," Modern industrial economy and informatization, vol. 10, no. 11, pp. 70-71, 2021.

[16] Y. Huang, "Analysis of power big data development under the situation of energy Internet," Modern industrial economy and informatization, vol. 10, no. 11, pp. 72-73, 2021.

[17] T. K. Brahmachary, S. Ahmed, and M. S. Mia, "Health, Safety and quality management practices in construction sector: a case study," Journal of System and Management Sciences, vol. 8, no. 2, pp. 47-64, 2021.

[18] Y. Sönmez, H. Kutlu, and E. Avci, "A novel approach in analyzing traffic flow by extreme learning machine method," Tehnicki vjesnik-Technical Gazette, vol. 26, no. 1, pp. 107-113, 2021. 